\title{
Using Private Contracts for Climate Change Mitigation
}

\author{
Kateřina Peterková Mitkidis*
}

DOI: $10.21827 / 5 a 86 a 7 e 10 \mathrm{e} 001$

\section{Keywords}

\author{
Climate Change Regulation; InTERnational Supply Chain Contracts; Carbon \\ EMISSIONS; PRIVATE REGULATION
}

\begin{abstract}
Regulation of climate change is caught up in a stalemate. Differences between developed and developing countries prevent reaching an international agreement. Transnational private regulation has unclear legitimacy, effectiveness and enforcement. National efforts are valuable, but their limited geographical reach creates incentives for companies to outsource environmentally heavy activities to countries with weaker regimes, the socalled "carbon leakage" effect. As a result the carbon emissions among international supply chains amount to multiple yearly emissions of some developed countries. This gap needs to be closed if we aim for effective global solutions to climate change. The majority of scholars agree that no single regulatory tool alone can remedy the situation, but that a combination of public and private, mandatory and voluntary regimes is necessary. The author proposes that supply chain contracts are the missing piece in the international climate change regulatory matrix. The article discusses why, despite their potential, supply chain contracts have hitherto experienced only little attention and why they can be successful where other regulation fails. It concludes that the potential of private contracting should be triggered by adequate regulation.
\end{abstract}

\section{Introduction}

The aim of this article is to bring attention to an often overlooked regulatory instrument for climate change mitigation - supply chain contracts. Despite intensive efforts to reach an international agreement on carbon emissions' reduction, ${ }^{1}$ the increasing number of national regulations, social pressure on companies to limit their environmentally harmful activities and raising public awareness, global society is not successful in mitigating the negative effects of climate change. Unequal development and the related clashing social and economic interests of developed and developing countries lie in the middle of the climate change conundrum. While most of the developed countries are prepared to

* The author, Katerina Peterkova ( $\mathrm{PhD}$, Master of Laws) is a research assistant at the Department of Law and the Arctic Research Center at the School of Business and Social Sciences, Aarhus University, Denmark. She is further a Board Member and Newsletter Editor at the Corporate Social Responsibility Legal Research Network, available online at <law.au.dk/forskning/projekter/csr-lrn/>.

1 Carbon emissions are for the purpose of this article understood as emissions of the six leading greenhouse gases (GHG), namely carbon dioxide (CO2), methane (CH4), nitrous oxide (N2O), hydrofluorocarbons (HFCs), perfluorocarbons (PFCs) and sulphur hexafluoride (SF6). 
commit to carbon emissions' reduction, developing countries are experiencing an economic and industrial boom and are not eager to give it up in order to mitigate a problem that is mainly caused by the historical activity of the developed part of the world. The result is that although national governments in developed countries adopt various laws and policies to limit carbon emissions of subjects under their jurisdiction, they indirectly create incentives for these subjects to outsource their environmentally heavy activities to countries with weaker environmental laws. This regulatory gap allowing companies to avoid responsibility for their carbon emissions abroad needs to be closed if we aim for effective global solutions to the climate change issue. Supply chain contracts may be the missing piece of the solution we are looking for. Having the form of a binding and enforceable legal instrument, contracts offer actual leverage over the parties' behaviour. And this is especially true when we speak about relationships between multinational companies and their suppliers from developing countries. If a multinational company imposes a concrete goal for carbon reduction on its suppliers through contracts, it may yield positive change without the necessity of reaching an international agreement through a costly and lengthy legislative process. As a consequence of such a contractual practice a new public local regulation may arise, creating law from bottom up rather than from top down.

However, why would companies, benefitting from the regulatory gap, voluntarily impose limits on their suppliers' carbon emissions? Since the latest negotiations have been to a large extent failing, an increasing number of private and public-private entities enter the regulatory area and create pressure on companies to adopt environmentally friendly regulations and behaviour. These entities include consumers, investors, NGOs, industrial associations and companies themselves. The pressure of private entities translates into various types of private regulation, such as transnational public-private initiatives, industrial and corporate codes of conduct, or reporting, monitoring and auditing schemes. Companies that do not comply with these legally non-binding regulations run reputational damage risks that can lead to public shaming in the media, drop in demand for their products, outflow of financing from environmentally responsible investors and losing competitive advantage against their peers. Therefore, in order to protect themselves and to manage related risks, an increasing number of companies implement environmental requirements in their supply chain management processes. Contractual provisions are one of the means able to influence suppliers' behaviour. However, since such requirements are often rather vague, sketching only the broadest line of good environmental behaviour, the enforcement of these requirements is an obvious concern. Nevertheless, facing the criticism of the low transparency of the supply chain control and the generally inadequate efforts invested into climate change mitigation and realising the possible advantages of environmentally thoughtful behaviour, more and more companies try to raise the expectations of their suppliers by implementing quantifiable and measurable objectives in relation to environmental issues.

The question remains whether such contractual requirements can have a significant effect in the global climate change mitigation effort. Although precise computations of potential carbon reduction in international supply chains are only scant, available estimates suggest that the capacity of supply chain contracting to reduce global carbon 
emissions is high. ${ }^{2}$ Therefore, successful use of its full potential can be a crucial component in an effective transnational climate change regulatory system.

In light of the foregoing, it is surprising that sustainable supply chain contracts do not attract as much attention as other private governance regimes. A reason may be that business contracts are generally bilateral arrangements, and therefore, their out-ofcontractual effects are not obvious or are unknown, not to mention their inability to be measured and verified. This article aims to remedy the lack of recognition of supply chain contracts' importance and discuss their potential in relation to carbon emissions reduction efforts.

The article starts with an overview of climate change regulation in Section II. Section III provides an overview of the development of scope 1, 2 and 3 emissions. ${ }^{3}$ Section IV follows with an analysis of supply chain contracts as a regulation type; namely, the questions of why supply chain contracts have been until now overlooked and why they may be successful where other regulation fails are discussed. Section V opens discussion on the quantifying of potential for emissions' reduction through contracts. Finally, the article closes with a conclusion in Section VI.

\section{Climate Change Regulation}

Although extensively discussed and increasingly regulated, climate change remains one of the most urgent issues of current society. To date, no single regulatory framework has provided satisfactory results and it is a common understanding that a combination of regulatory efforts is necessary to tackle this global problem. Scholars have suggested that a successful matrix for climate change mitigation will have to include various regulatory techniques, ranging from a binding international agreement, through national command and control regimes to global private regulation and voluntary corporate initiatives. ${ }^{4}$ The author proposes that the design of such a regulatory matrix should pay special attention to supply chain contracts, since they have significant potential for reduction of carbon emissions and may serve as a necessary link between public and private regulation and as a force for its enforcement. This section briefly describes the public and private realms in climate change mitigation that form the regulatory context of supply chain contracting.

\section{II.1. Public Regulation}

The international community of states recognises the environmental challenges and their negative effects on global health, economy, politics and social order, but it fails to reach an agreement on the commitments for reduction of carbon emissions that would effectively prevent further negative development. The 2009 United Nations Climate

See Section III below.

Scope 1 emissions: emissions that are directly produced by sources owned or controlled by the regulated entities; scope 2 emissions: emissions that are produced indirectly from generation of electricity purchased by the entities; scope 3 emissions: emissions that are consequences of the regulated entities' activities, but produced by sources outside of the entities' ownership or control, see Carbon Disclosure Project, Technical Note: Glossary of terms, available online at <www.cdproject.net/Documents/Guidance/2012/Technical/glossary-of-terms.pdf> (accessed 1 November 2013).

4 Vandenbergh, M. P. and Cohen, M. A., "Climate Change Governance: Boundaries and Leakage", New York University Environmental Law Journal, vol. 18, ed. 2, 2010, 221-292, 223. 
Change Conference in Copenhagen was a clear example of the stalemate we experience nowadays: being aware of the urgent need for international cooperation to tackle the global climate change issue, but unable to find the means, and many times also the will, to do so. The failure to agree on new national reduction targets of carbon emissions that would be a continuance of the Kyoto Protocol ${ }^{5}$ showed the persisting political and economic sensitivity of the climate change discussions and put any hopes for a timely and effective international solution on hold. Even though the Kyoto Protocol has been extended at the last minute for a second commitment period until 2020, ${ }^{6}$ its effectiveness is doubtful provided that major global emitters are not among the Protocol signatories, nor does it set specific reduction targets. From the twenty highest emitting countries in the world, only six bound themselves to reach specific targets for carbon emissions' reduction under the Kyoto Protocol for the period between 2013 and 2020. That is a very low number, since the remaining fourteen countries, including China, USA, India and Russia, representing about $70 \%$ of all global emissions, alongside all lower emitters, are not captured by the binding agreement. ${ }^{7}$ In fact, the extended Kyoto Protocol legally binds countries representing less than $15 \%$ of global emissions. ${ }^{8}$ Thus, our expectations regarding future international negotiations on the climate change issue should not be high, since the gap between the interests of developed and developing countries in this respect is not only not closing but rather is extending over time.

One of the strongest (and hardest to fight) arguments of the developing countries is the claim that the current levels of GHG emissions in the atmosphere are the product of past activities of the developed countries, which should take responsibility for the current situation. The developing world points out the unfairness of the situation when it is expected to socially, politically and economically develop under the adverse state of the current climate and concurrently participate in climate change mitigation, although its contribution to the current situation was substantially lower than the contribution of the developed countries. ${ }^{9}$ Developing countries call for the same space and rights to growth and wealth as developed countries had during their economic and industrial boom. Even

5 Kyoto Protocol to the United Nations Framework Convention on Climate Change, 10 December 1997; 37 ILM 22 (1998), available online at <unfccc.int/key_documents/kyoto_protocol/items/6445.php> (accessed 31 October 2013).

6 United Nations, Draft decision proposed by the President, Amendment to the Kyoto Protocol pursuant to its Article 3, paragraph 9, 8 December 2012, FCCC/KP/CMP/2012/L.9, available online at $<$ unfccc.int/resource/docs/2012/cmp8/eng/109.pdf > (accessed 31 October 2013).

7 According to the U.S. Energy Information Administration the world total carbon dioxide emissions from energy consumption in 2011 amounted to 32,578.645 million metric tons. The largest twenty emitters were identified as follows (in million metric tons): China $(8,715.307)$, USA $(5,490.631)$, Russia (1,788.136), India (1,725.762), Japan (1,180.615), Germany (748.486), Iran (624.855), South Korea (610.954), Canada (552.557), Saudi Arabia (513.527), UK (496.799), Brazil (475.409), Mexico (462.293), South Africa (461.565), Indonesia (426.790), Italy (400.939), Australia (392.286), France (374.327), Spain (318.644), Poland (307.911). U.S. Energy Information Administration, International Energy Statistics, available online at <www.eia.gov/cfapps/ipdbproject/iedindex3.cfm?tid=90\&pid= 44\&aid=8\&cid=regions\&syid=1980\&eyid=2010\&unit=MTCDPP> (accessed 8 April 2014).

8 Climate Policy Initiative, Rom-Povolo, E., Policy Watch: UN climate talks wrap up, Indonesia approves landmark forest protection deal, and Africa's largest solar plant close to breaking ground, December 2012, at $<$ climatepolicyinitiative.org/2012/12/11/policy-watch-un-climate-talks-wrap-up-indonesia-approveslandmark-forest-protection-deal-and-africas-largest-solar-plant-close-to-breaking-ground/> (accessed 31 October 2013).

9 For detailed argumentation see Third World Network, Developing countries call for historical responsibility as basis for Copenhagen Outcome, TWN Bonn News Update No. 9, 5 June 2009. 
though the developed countries acknowledge substantiation of this claim, ${ }^{10}$ it is evident that the condition of the climate will not improve or maybe better said stop deteriorating without the active involvement of all the big emitters regardless of the stage of their development. ${ }^{11}$ It is important to say that even if we had a binding international agreement under which all countries committed to specific goals, national governments would need to translate this commitment into adequate laws and policies to secure the actual compliance of subjects under their jurisdiction. This proved to be a highly demanding task under the Kyoto Protocol, where for example the inability to reach the stipulated goals forced Canada to withdraw from the agreement. ${ }^{12}$

The situation looks brighter at the national level. A number of countries adopt national plans and regulation for climate change mitigation regardless of their commitment on the international level. For example, the EU is obliged to integrate environmental considerations into all its policies and decisions. ${ }^{13}$ Under this imperative, it has not only committed to reduce emissions under the second Kyoto Protocol period, but also implemented the EU Emissions Trading System, building an international carbon market, ${ }^{14}$ and has adopted or is working on adopting a number of policies and regulations, such as the Environmental Action Plan, ${ }^{15}$ the Energy Efficiency directive, ${ }^{16}$ or the Product Environmental Footprint (PEF) Guide. ${ }^{17}$ We can also see a difference in the attitude of some of the less developed countries. For example, Brazil has adopted the National Climate Change policy, which sets emissions reduction targets although Brazil has no such obligation under the Kyoto Protocol. ${ }^{18}$

10 See Preamble to the United Nations Framework Agreement on Climate Change, 1992, 1771 UNTS 107: 'Noting that the largest share of historical and current global emissions of greenhouse gases has originated in developed countries, that per capita emissions in developing countries are still relatively low and that the share of global emissions originating in developing countries will grow to meet their social and economic development'.

11 Supra nt. 9, 2. Mr. Martin Khor, Director of the South Centre noted that: '[d]eveloped countries would need to reduce their emissions by $213 \%$ by 2050, for developing countries to maintain their current per capita emissions level'; see also supra nt. 4, 222.

12 CBC News, Politics, Canada pulls out of Kyoto Protocol, 12 December 2011, at <www.cbc.ca/news/politics/story/2011/12/12/pol-kent-kyoto-pullout.html> (accessed 11 February 2014).

13 Consolidated Version of the Treaty on the Functioning of the European Union, 2010 O. J. C 83/47, article 11: 'Environmental protection requirements must be integrated into the definition and implementation of the Union policies and activities, in particular with a view to promoting sustainable development'.

14 Directive 2003/87/EC of the European Parliament and of the Council of 13 October 2003 establishing a scheme for greenhouse gas emission allowance trading within the Community and amending Council Directive 96/61/EC, 2003 O. J. L 275/32.

15 European Commission, Proposal for a Decision of the European Parliament and of the Council on a General Union Environment Action Programme to 2020, Living well, within the limits of our planet, Brussels, 29 November 2012, COM(2012) 710 final.

16 Directive 2012/27/EU of the European Parliament and of the Council of 25 October 2012 on energy efficiency, 2012 O. J. L 315/1.

17 European Commissions, Joint research centre, Product Environmental Footprint (PEF) Guide, Ref. Ares (2012) 873782, 17 July 2012.

18 The Brazilian National Climate Change Policy was adopted through law no. 12.187 of 29 December 2009, available online at <www.planalto.gov.br/ccivil_03/_Ato2007-2010/2009/Lei/L12187.htm> (accessed 31 October 2013). 


\section{II.2. Carbon Leakage As A Product of Unequal National Regulations}

Nevertheless, however important national policies are in combating climate change, they alone are not sufficient and, in some cases, may even have negative effects. Climate change is a global issue. Unequal regulation in different countries creates incentives for companies to outsource their environmentally harmful activities from countries with strict policies to countries with weaker regimes. ${ }^{19}$ Hence, we stand at an impasse; having (or developing) rather effective regulation of corporate environmental behaviour on the national level, but allowing companies to avoid their responsibility by moving their activities abroad. Outsourcing to developing countries means not only increased emissions during the manufacturing process due to lower technological development, but also causes an increase in the carbon footprint of the products due to the need for transportation of the finished goods to the buyer and consumers. This phenomenon, called "carbon leakage", is an important concern, questioning the very nature of national regulatory efforts and their effectiveness.

It is not easy or even possible to prove a causal link between the steep increase of carbon emissions in developing countries and national environmental laws and policies in developed countries. However, it is a fact that a large fraction of carbon emissions in developing countries can be attributed to goods exported to consumers in developed countries. ${ }^{20}$ For instance, Herrmann and Hauschild calculated that due to imports from China, the UK avoided circa sixteen million tons of CO2 emissions in 2004; this is approximately six times more than in $1992 .{ }^{21}$ Moreover, the products exported from China to the UK in 2004 carried almost 130 million tonnes of embedded CO2. The ratio between the carbon efficiency of UK and Chinese production methods in 2004 furthermore shows that three times more $\mathrm{CO} 2$ is emitted during production in China than it would be in the production of the same product in the UK. ${ }^{22}$ These calculations do not offer evidence that the outsourcing trend is caused by environmental regulation in developed countries. However, they point towards the focus of developed countries on the environmental impacts from power production, carbon taxes and generally stricter environmental regimes as one of the driving forces for geographical shift of manufacturing activities. ${ }^{23}$

19 European Commission, Communication from the Commission to the European Parliament, the Council, the European Economic and Social Committee and the Committee of the Regions, Analysis of options to move beyond 20\% greenhouse gas emission reductions and assessing the risk of carbon leakage, Brussels, 26.5.2010, COM(2010) 265 final, section 4; supra nt. 4, 262 et seq.

20 See e.g. Guan, D., Peters, Glen P., Weber, C. L. and Hubacek, K., "Journey to world top emitter: An analysis of the driving forces of China's recent CO2 emissions surge", Geophysical Research Letters, vol. 36, ed. 4, 2009, 1-5 (Concluding that 'developed countries are responsible for over half of the growth in Chinese exported carbon emissions from 2002 to 2005'); Wang, T., Watson, J., Who Owns China's Carbon Emissions?, Tyndall Centre for Climate Change Research, Tyndall Briefing Note No. 23, October 2007 (noting that 'consumption in OECD countries that import goods from the developing world does not only generate emissions within those countries - but also contributes to growing emissions in the developing world').

21 Herrmann, I. T., Hauschild, M.Z., "Effects of globalization on carbon footprints of products", CIRP Annals - Manufacturing Technology, vol. 58, ed. 1, 2009, 13-16, 14.

22 Id., 14-15.

23 Id., 16. 
Irrespective of the actual cause, two major concerns are usually associated with the carbon leakage problem: firstly, creation of carbon havens, i.e. countries intentionally attracting carbon-heavy industries and, thus, undermining global emissions reduction efforts; and secondly, massive relocation of jobs into the countries with weak environmental regulation. ${ }^{24}$ Although we have not experienced either of these to a massive extent yet, the future matrix of climate change regulation must be designed in such a way that it will prevent these consequences.

Until now, at least three ways were suggested to address the carbon leakage problem. The first and most straightforward solution is the approximation of climate change mitigation efforts between countries with various levels of environmental regulation. As discussed earlier, a global agreement appears to be a too demanding and long-term task. However, countries could cooperate on bilateral or industry levels, where reaching a consensus could be easier. ${ }^{25}$ Nevertheless, this solution will always be only partial and will not tackle the global character of the climate change problem.

Secondly, countries with a stricter carbon emission regime could impose higher costs for imports from locations with weaker regulation. However, such a system would have to be scrutinised under the WTO requirements to ensure that it does not constitute a barrier to international trade. ${ }^{26}$ Moreover, the practicalities of implementation could pose a problem, especially in relation to controlling compliance of manufacturers in countries where monitoring and reporting systems are not well developed.

Finally, an indirect way through regulation of corporate reporting that would demand disclosure of emissions from all supply chain members was proposed as one of the possible solutions. ${ }^{27}$ Some countries have imposed on companies the obligation to regularly report the amount of greenhouse gas emissions produced. For example, under the US Clean Air Act, ${ }^{28}$ this obligation applies to facilities ${ }^{29}$ that produce more than 25,000 metric tons of carbon dioxide equivalent (CO2eq) per year. However, the obligation concerns only direct emissions of the facilities, excluding emissions of the production chain. If the regulator included supply chains' emissions in the legal reporting obligation, companies would lose the incentive to relocate their environmentally damaging activities to other countries, since they would be forced by law to disclose their suppliers' emissions and, therefore, be accountable for them anyway. However, such a requirement would impose extensive administrative and financial burdens on the companies.

Whichever solution to the carbon leakage problem we choose, a crucial question is how to change the production processes and behaviour of the suppliers from developing countries in such a way that outsourcing would remain profitable while their carbon

24 United Nations Environment Programme and the World Trade Organization, REPORT: Trade and Climate Change, 2009, 99.

25 Supra nt. 19, 12.

26 For the discussion on applicability of the WTO rules see supra nt. 24 at 103 et seq. See also Cohen, M. A. and Vandenbergh, M. P., "The potential role of carbon labeling in a green economy", Energy Economics, vol. 34, sup.S1, 2012, S53-S63, S59-S60 (discussing the trade related challenges of carbon labelling; pointing out that private voluntary standards would more easily be accepted by the international trade rules than public mandatory requirements).

27 Supra nt. 4.

28 Clean Air Act, 42 U.S.C. $\$ 7401$ et seq., 1970.

29 The law works on the facility level. Therefore, companies may possibly avoid the reporting obligation by portioning their production. 
emission levels would drop. Supply chain contracts may be one of the solutions we are looking for.

\section{II.3. Private Regulation}

Public regulation of scope 3 carbon emissions is in its infancy. International law, having troubles in the scope 1 and 2 emissions, is missing completely in relation to scope 3 emissions. National governments discuss possible regulatory means and their consequences and compatibility with other regulation on the national and international level, but up-to-date laws affect scope 3 emissions only indirectly. Therefore, in the current situation, private regulation prevails in the area. Private regulation may be defined as regulation developed by non-state actors whose 'legitimacy, governance, and implementation is not rooted in public authority'. ${ }^{30}$ It can have various forms, ranging from transnationally agreed standards, such as the ISO standards, ${ }^{31}$ through industrial initiatives, ${ }^{32}$ to corporate codes of conduct. ${ }^{33}$ However, private regulation suffers from several deficiencies regarding its legitimacy, effectiveness and monitoring and enforcement. The legitimacy of private regulation is not derived from sovereign states and their institutions (as in case of national and international law). Private regulators are not democratic representatives of global citizens. Therefore, the authority and binding power of private regulation is often questioned and criticised by legal theory and political science. $^{34}$

Effectiveness is another drawback of private regulation. It is challenged not only by unclear legitimacy, but also by the lack of verifiable reporting and monitoring systems. ${ }^{35}$

30 Vogel, D., "The private regulation of global corporate conduct", Business \& Society, vol. 49, ed. 1, 2010, 68-87, 69.

31 ISO, "Greenhouse gases--Quantification and reporting of greenhouse gas emissions for organizations-Guidance for the application of ISO 14064-1", ISO/TR 14069:2013 Greenhouse. ISO, "Greenhouse gases--Carbon footprint of products--Requirements and guidelines for quantification and communication", ISO/TS 14067:2013. ISO "Guidance on Social Responsibility", ISO 26000:2010, section five and note especially section 6.5.5.2.1, which states that: "To mitigate climate change impacts related to its activities an organization should: - identify the sources of direct and indirect accumulated GHG emissions and define the boundaries (scope) of its responsibility; - measure, record and report on its significant GHG emissions, preferably using methods well defined in internationally agreed standards (see also Annex A for examples of initiatives and tools addressing GHG emissions); implement optimized measures to progressively reduce and minimize the direct and indirect GHG emissions within its control and encourage similar actions within its sphere of influence;...". (emphasis added) Annex A includes CDP initiative).

32 For example the Electronic Industry Citizenship Coalition has developed the EICC Carbon Reporting System, which allows companies to measure and share emissions data with their customers in a standardised template, Electronic Industry Citizenship Coalition, Environmental Sustainability, 20 November 2012, available online at <eicc.info/ESWG.shtml> (accessed 1 November 2013).

33 For example Coca Cola Comp. suggests to its suppliers as a good practice to measure 'emissions, water and energy usage and sets goals to minimize environmental impact overtime', see Coca Cola Company, Supplier Guiding Principles, Global Workplace Rights Workplace Rights Implementation Guide 2011, 48, available online at <assets.cocacolacompany.com/d7/e9/5ea51d374870bbd1409c3a584807/SupplierSGPImplementationGuideENG LISH.pdf $>$ (accessed 1 November 2013).

34 Lambooy, T.E., Corporate Social Responsibility. Legal and semi-legal frameworks supporting CSR, Kluwer, Deventer, 2010, 256 et seq.

35 Jonge de, A., "Transnational corporations and international law: Bringing TNCs out of the accountability vacuum", Critical Perspectives on International Business, vol. 7, ed.1, 2011, 66-89, 72. 
Compliance is most often controlled via suppliers' self-reporting and audits conducted by companies themselves or by third party auditors, without any connection to public authorities or formal legal enforcement processes. This leads to doubts about the quality and effectiveness of CSR audits. ${ }^{36}$ The unconvincing compliance-monitoring then undermines enforceability. Legally non-binding private regulation is not subject to judicial review. However, courts or tribunals may invoke it indirectly, using other legal instruments, such as advertising law, labour law or contract law. ${ }^{37}$

Nevertheless, private regulation plays an important role in regulation of transnational companies although it is based on voluntary participation. It has the ability to affect companies' behaviour to a considerable extent, since it is driven by their interest in reputation-building among their peers, investors and public; in other words by the objective of risk management, maintenance of the social license to operate and long-term profitability. Good reputation is an important asset, especially for branded and multinational companies. Reputational damage can have far-reaching business and economic consequences, such as decrease in sales, losing business partners or competitive advantage. In the current society of environmentally conscious consumers and investors, companies' transparency about their carbon emission levels, as well as the ones of their supply chains, are crucial in the reputational risk management. But the risk connected to the engagement of companies into climate change mitigation efforts is not limited to reputation only. Legal risk management is also an important concern. As discussed above, national governments adopt a growing number of legislation aiming at the reduction of carbon emissions that affect the way business is done. And more regulation is expected to come. ${ }^{38}$ Companies most often express their concern in relation to future regulation of carbon tax, emissions reporting obligations, fuel and energy taxes and cap and trade schemes. ${ }^{39}$ Proactive attitude towards risk of future regulation helps companies to be prepared for the upcoming obligations, gain competitive advantage against their peers, who do not take preventive measures, and boost their reputation as environmentally conscious companies. ${ }^{40}$

Maintaining a good reputation is also inseparably connected to the social licence to operate. Social licence to operate can be understood as the expectations of a company's

36 For a critical view on social audits see Swift, T. A. et al., "The new social audits: Accountability, managerial capture or the agenda of social champions?", European Accounting Review, vol. 9, ed. 1, 2000, 81-98.

37 See e.g. Kenny, K. E., "Code or Conduct: Whether Wal-Mart's Code of Conduct Creates a Contractual Obligation between Wal-Mart and the Employees of Its Foreign Suppliers", Northwestern Journal of International Law \& Business, vol. 27, ed. 2, 2007, 453-474; or Sobzak, A., "Are Codes of Conduct in Global Supply Chains really Voluntary? From Soft Law Regulation of Labour Relations to Consumer Law", Business Ethics Quarterly, vol. 16, ed. 2, 2006, 167-184.

38 For example, the Danish Financial Statement Act was recently updated, so that companies are now obliged to report on the measures they take in relation to climate change and the implementation and results of those measures. CSRgov.dk, Proposal for an Act amending the Danish Financial Statements Act. (Report on social responsibility for large businesses), December 2008, available online at $<$ csrgov.dk/file/319999/proposal_report_on_social_resp_december_2008.pdf> (accessed 1 November 2013).

39 Concerns regarding future regulation are a standardised part of the CDP reports. The reports are accessible through Carbon Disclosure Project database, available online at <cdproject.net/enUS/Results/Pages/responses.aspx> (accessed 1 November 2013).

40 Haapio, H., ed., A Proactive Approach to Contracting and Law, Turku University of Applied Science, Course material 38, Turku, 2008. 
stakeholders in relation to the manner in which the company conducts business. ${ }^{41}$ Living up to the stakeholders' basic expectations proved to be crucial for continuance of a business and protecting investments. ${ }^{42,43}$ From its definition, legal compliance is an inherent part of the social licence to operate. However, stakeholders' expectations go often far beyond legal requirements. The content of social licence to operate will typically include respect for human rights, environmental protection, business integrity and local communities. As the awareness of the climate change challenges spreads through all levels of society, the demand for carbon reduction becomes an important issue. Raising awareness is facilitated by activities of both state and non-state actors. The non-profit organization Carbon Disclosure Project (CDP) $)^{44}$ is an example of the latter, making the disclosure of corporate carbon emissions' levels a business norm and the expectation of transparency a part of the social licence to operate. As far as the former, possible future implementation of regulation on carbon footprint of commercial products in the EU is likely to increase demand for products with low level of embedded carbon emissions. ${ }^{45}$ Therefore, in order to avoid negative effects of the new regulation on their social licence to operate, companies should commence the process of calculating the life-cycle carbon emissions of their products.

In the climate change area, the CDP's system for corporate reporting of greenhouse gases that uses the Greenhouse Gas Protocol (GHG Protocol) as an accounting tool is the most known private regulation. In 2011, the GHG Protocol issued the Corporate Value Chain (Scope 3) Accounting and Reporting Standard (GHG Scope 3 Standard) containing guidance for scope 3 emissions' detection and reporting and CDP launched its CDP Supply Chain Program. ${ }^{46}$ The number of companies participating voluntarily in CDP is constantly increasing, and in 2012 fifty-four of the world's biggest companies and almost 2,500 of their suppliers took part in the CDP Supply Chain Program, reporting on their own carbon emissions and on carbon emissions of their supply chains. ${ }^{47}$ Even

41 Gunningham, N., Kagan, R. A. and Thornton, D., "Social License and Environmental Protection: Why Businesses Go Beyond Compliance", Law \& Social Inquiry, vol. 29, ed. 2, 2004, 307-341, 308.

42 An example where losing a social licence to operate led to closing of a business was the activity of Coca Cola in Kerala, India. Coca Cola, who needed large quantities of water for production activities, caused severe shortages of water in the locality. Inhabitants of nearby villages had since 2002 protested repeatedly against the overuse of local water resources. After long court proceedings, Coca Cola closed the facility in 2007. For more information, see The Rights to Water and Sanitation, Case against CocaCola Kerala State: India, 20 August 2010, available online at <righttowater.info/?s=coca+cola+kerala+ state+india> (accessed 1 November 2013).

43 Wilburn, K. M. and Wilburn, R., "Achieving Social License to Operate Using Stakeholder Theory", Journal of International Business Ethics, vol., 4, ed. 2, 2012, 3-16, 4; Nelsen, J. L., "Social license to operate", International Journal of Mining, Reclamation and Environment, vol. 20, ed. 3, 2006, 161-162, 161.

44 Carbon Disclosure Project, available online at <www.cdp.net/en-US/Pages/HomePage.aspx> (accessed 8 April 2014).

45 For more information on the CO2 labelling plans in the EU see EurActiv, Neslen, A., EU Wants Carbon Labels to do What They Say on the Tin, 4 July 2012, available online at <euractiv.com/specialreportprods-green-planet/eu-wants-carbon-labels-tin-news-513629> (accessed 4 March 2014).

46 Greenhouse Gas Protocol, Corporate Value Chain (Scope 3) Accounting and Reporting Standard, available online at <ghgprotocol.org/standards/scope-3-standard> (accessed 1 November 2013); Carbon Disclosure Project, Supply Chain Program, available online at <cdproject.net/enUS/Programmes/Pages/CDP-Supply-Chain.aspx> (accessed 1 November 2013).

47 Carbon Disclosure Project, Reducing Risk And Driving Business Value: CDP Supply Chain Report 2012-13, 6, available online at <cdproject.net/CDPResults/CDP-Supply-Chain-Report-2013.pdf> (accessed 1 November 2013). 
though this is a good achievement, we have to bear in mind the limits of private regulations. Voluntary reporting schemes are an essential part of the climate change regulatory matrix providing for necessary transparency and thus public control of companies', and their suppliers', emissions. However, standing alone these schemes do not guarantee the enforcement of positive shifts in companies' behaviour in respect to the environment.

\section{The Relations Between Scope 1, 2 and 3 Emissions}

Observing the development of national emissions in the last decade, one has to notice the divide between major developed and major developing countries. While the CO2 emissions of the EU countries, USA or Canada dropped in 2010 by some per cent, in comparison to the results from 2000 (e.g. Germany -7\%, UK -5\%, Italy $-7 \%$, USA $-4 \%$, Canada $-4 \%),{ }^{48}$ the emissions of booming economies of developing countries has grown rapidly by tens and hundreds per cent with China leading the group with almost tripled emissions since 2000 (e.g. China 191\%, Vietnam 145\%, Bangladesh 93\%, Thailand 72\%, India 69\%). ${ }^{49}$

Some may consider the comparison of absolute numbers unfair, since it does not account for the population size. The emissions per capita show us at first a completely different picture, with the USA and Australia being amongst the top emitters with circa 18 metric tons per person, compared to 1.4 tons per person in India. However, observing the decreasing/increasing tendencies, we find that the numbers do not differ much from the tendencies of overall national emissions. Emissions per capita have risen significantly in developing countries during the last decade (China 177\%, Vietnam, 116\%, Bangladesh $64 \%$, Thailand $60 \%$, India $45 \%$ ), while at the same time they decreased slightly in the developed countries (USA $-13 \%$, Germany $-7 \%$, Canada $-12 \%$, UK $-10 \%$, Italy $-7 \%$ ). ${ }^{50}$ Chinese per capita emissions reached the level of European countries in 2011, and more countries may quickly follow. ${ }^{51}$ The tendencies can be attributed to different stages of development combined with different energy and fuels policies. Whereas developed countries focus in recent years on using cleaner energy and limiting the use of fossil fuels, developing countries multiplied the use of fossil fuels due to the intensive industrialisation.

48 U.S. Energy Information Administration, supra nt. 7. Although the results seem positive, the EU will have to intensify its efforts in order to reach the $-20 \%$ target of the second commitment period of the Kyoto Protocol. The USA progressed well after the emission peek in 2007; however, experienced a slight relapse in 2010. Therefore, the challenge lies in stabilisation of the decreasing tendency. Canada's emissions have been constantly decreasing over the last four years, nevertheless, Canada decided to withdraw from the Kyoto Protocol at the end of 2011 in order to avoid large penalties due to the inability to reach the commitment of $6 \%$ drop by 2012 compared to the 1990 base year.

49 U.S. Energy Information Administration, supra nt. 7.

50 For more information on developments of emissions see International Energy Agency, CO2 Emissions from Fuel Combustion, Highlights, 2012, at <iea.org/publications/freepublications/publication/ name,32870,en.html> (accessed 1 November 2013).

51 European Commission, Joint Research Centre, Per capita CO2 emissions in China reach EU levels, 18 July 2012, available online at <ec.europa.eu/dgs/jrc/index.cfm?id=1410\&dt_code=NWS\&obj_id= 15150\&ori=RSS $>$ (accessed 1 November 2013), informing that Chinese per capita emissions in 2011 reached 7.2 tonnes, which is comparable to 7.5 tonnes per capita emission of the EU. 
However, as the numbers look fairly nice for developed countries and miserable for countries developing, a critical piece of information is missing from the reported and published data: the emissions embedded in imported products. According to Peters et al., in 2011 the CO2 emissions embedded in products intended for export accounted for $26 \%$ of the global CO2 emissions. ${ }^{52}$ China, as a major exporter and major emitter, has been the subject of most calculations regarding emissions embedded in exported products. For instance, Wei et al. stated that carbon emissions generated during production for export amounted in 2007 to $35 \%$ of total Chinese emissions. ${ }^{53}$ However, let us consider the situation from the other side, i.e. from the perspective of a developed country. While the UK's national CO2 emissions from the consumption of energy have raised only slightly from 577,03 million metric tonnes in 1992 to 583,42 in $2004,{ }^{54}$ which equals to a $1 \%$ increase, the emissions imported with the products from China increased from 26 to 128 million metric tonnes. ${ }^{55}$ If we add the emissions embedded in import to the total national emissions number, we find that the overall emissions have actually increased by $23 \%$.

This problem is not unknown. ${ }^{56}$ The obligation of states to disclose the embedded emissions of imported products has been suggested as a possible solution to achieve a more transparent picture of global distribution of carbon emissions. ${ }^{57}$ As transparency on the national level is certainly important in this respect, the actual change of attitude to the environmental aspects of businesses in both developed and developing countries is crucial, because as discussed above, the international solution is nowhere to be seen. Therefore, the challenge of upcoming years will be to use all available tools, develop new ones and combine them in order to achieve a reduction of carbon emissions in production in developing countries without the need for a top-down international public regulation.

\section{Contracts As Regulatory Tools}

In the light of the foregoing, we are in a situation where governments know about the problem of the increasing amounts of carbon emissions being transported from developing to developed countries, whether this is caused by climate change policies of the developed countries (carbon leakage) or not, but are not able to secure improvement

52 Peters, G. P. et al., "Growth in Emission Transfers via International Trade from 1990 to 2008", PNAS, vol. 108, ed. 21, 2011, 8903-8908, 8903. The authors build an estimation model of the net transfers of $\mathrm{CO} 2$ emissions via international trade, where ' $[\mathrm{t}]$ he net emission transfers represents the $\mathrm{CO} 2$ emissions in each country to produce exported goods and services minus the emissions in other countries to produce imported goods and services'.

53 Wei, B., Fang, X. and Wang, Y., "The Effects of International Trade on Chinese Carbon Emissions", Journal of Geographical Sciences, vol. 21, ed. 2, 2011, 301-316, 307.

54 U.S. Energy Information Administration, supra nt. 7.

55 Herrmann and Hauschild, supra nt. 21, 14.

56 The topic appeared several times in the media (see e.g. BBC News, Harrabin, R., Openness Urged on UK's Emissions, 3 September 2010, available online at <bbc.co.uk/news/science-environment-11172239> (accessed 1 November 2013); or BBC News, Harrabin, R., Carbon emissions 'hidden' in imported goods revealed, 25 April 2011, available online at <bbc.co.uk/news/science-environment-13187156> (accessed 1 November 2013) and is a subject of a range of research projects and publications (for literature review see e.g. Peters et al., supra nt. 52, 3903, or Guo, J., Zhang, Z. and Meng, L., "China's provincial CO2 emissions embodied in international and interprovincial trade", Energy Policy, vol. 42(C), 2012, 486-497, 489).

57 Herrmann and Hauschild, supra nt. 21, 16. 
of the situation due to the lack of international consensus and necessity to respect the international trade rules. Companies are, however, not bound by the same ties as governments are, ${ }^{58}$ while concurrently they have a growing political and regulatory influence. ${ }^{59}$ With their strong economic power and transnational reach, ${ }^{60}$ companies have the means to affect political and legislative processes (most obviously by lobbying, ${ }^{61}$ sponsoring political campaigns ${ }^{62}$ and signing bilateral investment agreements with national governments ${ }^{63}$ ), as well as the life conditions of individuals (through environmental effects of their operation or employment conditions ${ }^{64}$ ), and other business entities worldwide, and especially members in their supply chains. From being the governed they are becoming governing entities, however without being subjected to the obligations under international law. ${ }^{65}$

Given the foregoing, we may assume that multinational western-based companies can influence not only their national climate change policies, but that they also have the ability to change and control activities of their business partners in respect to the environment. This is relevant especially in relation to business partners from developing countries that are often economically dependent on the demand from foreign multinationals. Both private and public regulators are aware of this possibility and create pressure on companies to use the control power in their sphere of influence. ${ }^{66}$ Contracts

58 Vogel, supra nt. 30, 75, noting that in contrast to states, who are restricted by WTO rules, companies may demand adherence to their codes of conducts and CSR standards as a precondition for doing a business.

59 Institute for Policy Studies, Anderson, S. and Cavanagh, J., REPORT: Top 200: The Rise of Corporate Global Power, 4 December 2000, updated version 2006, Washington, 3: '[o]f the 100 largest economies in the world, 51 are corporations; only 49 are countries (based on a comparison of corporate sales and country GDPs)'.

60 United Nations Conference on Trade and Development (UNCTAD), REPORT: World Investment Report 2009, vol. 1, Transnational Corporations, Agricultural production and Development, 2009, New York and Geneva, 17, showing that in 2009 there were approximately 82,000 transnational corporations worldwide and the largest one hundred of them accounted for about $4 \%$ of world GDP.

61 Anderson and Cavanagh, supra nt. 59: '[t] he exact amount spent on these activities (lobbying) is not known, but of the Top 200 firms, ninety four maintain 'government relations' offices located on or within a few blocks of the lobbying capital of the world Washington, DC's K Street Corridor.'; for the discussion on lobbying in the EU, see Bernhagen, P. and Mitchell, N. J., "The Determinants of Direct Corporate Lobbying in the European Union", European Union Politics, vol. 10, ed. 2, 2009, 155-176, 163, citing Greenwood, J., Interest Representation in the European Union, 2nd ed., Palgrave Macmillan, London, 2007, stating that '.. around $85 \%$ of all EU-level groups are 'located within a $21 / 2$ hour train ride from Brussels'.

62 Anderson and Cavanagh, supra nt. 59.

63 Pace University School of Law, Institute of International Commercial Law and International Association for Contract and Commercial Management, REPORT: The Triple Bottom Line: The Use of Sustainability and Stabilization Clauses in International Contracts, 2011, New York, 30-36, empirical investigation of the use of so-called "stabilization clauses" by companies across the world; Jonge de, supra nt. 35, 69.

64 The scope of influence may be represented by the number of people employed by transnational corporations. This number has increased up to about seventy seven million in 2008, i.e. approximately four times more than in 1982; see UNCTAD, supra nt. 60.

65 See Jonge de, A., Transnational Corporations and International Law: Accountability in the Global Business Environment, Edward Elgar Publishing, Northampton, 2011; de Jonge, supra nt. 35.

66 The term "sphere of influence" is used by several regulations, such as the UN Global Compact (Introductory text) or ISO 26000 (par. 2.19). The interpretation of the term has caused many discussions. The ISO 26000 standard provides the following definition: 'range/extent of political, 
then come as natural tools for executing such a control. For instance, ISO 26000 states that: 'To promote social responsibility in its value chain, an organization should: integrate ethical, social, environmental and gender equality criteria, and health and safety, in its purchasing, distribution and contracting ... ${ }^{67}$ Further, it lists 'setting of contractual provisions or incentives' as the first example of exercising influence over companies' business partners. ${ }^{68}$ While acknowledging that the ability to influence companies' suppliers depends on various factors, such as the number of suppliers (i.e. level of dependence on a specific supplier) or the complexity of the supply chain, the OECD Guidelines for Multinational Enterprises provide that 'enterprises can also influence suppliers through contractual arrangements' ${ }^{69}$ More specifically regarding the $\mathrm{CO} 2$ emissions, the GHG Protocol relies on contractual arrangement between the reporting company and its suppliers as leverage to acquire the data on suppliers' emissions. $^{70}$

\section{IV.1. Why Are Contracts Overlooked in the Climate Change Regulation Matrix?}

From the above we can conclude that companies, and especially multinational companies, have the power as well as the tools - contracts - to influence their suppliers' behaviour. So why has contractual governance not been discussed and developed more in relation to the climate change efforts?

Firstly, supply chain contracts were traditionally drafted with the sole purpose to regulate behaviour regarding the exchange of goods and money between two parties. However, they have gradually included an increasing number of provisions whose aim is to protect third parties' interests rather than economic interests of the contracting parties. These provisions do not directly relate to the subject matter of a contract, which in the case of supply chain contracts means the tangible quality of the delivered products. ${ }^{71}$ Requirements for $\mathrm{CO} 2$ monitoring and reduction in suppliers' production and other processes and activities are a typical example of these provisions. For example, BT group

contractual, economic or other relationships through which an organization (2.12) has the ability to affect the decisions or activities of individuals or organizations' (emphasis added). See UN Global Compact and International Standard ISO 26000 Guidance on Social Responsibility, An Introduction to Linkages between UN Global Compact Principles and ISO 26000 Core Subjects, 4 March 2014, available online at <unglobalcompact.org/docs/news_events/8.1/UNGC_ISO_Final.pdf> (accessed 4 March 2014). For further discussion on the term see e.g. Woods, S., "Four varieties of social responsibility: Making sense of the 'Sphere of influence' and 'Leverage' debate via the case ISO 26000", Osgoode CLPE Research Paper, no. 14/2011; or UN Human Rights Council, Clarifying the concepts of 'sphere of influence' and 'complicity', $A / H R C / 8 / 16,2008$, available online at <refworld.org/docid/484d1fe12.html> (accessed 4 March 2014).

67 ISO 26000, par. 6.6.6.2.

68 ISO 26000, par. 7.3.3.2.

69 The OECD Guidelines for Multinational Enterprises, Commentary on General Policies, par. 21, available online at <www.oecd.org/corporate/mne/> (accessed 8 April 2014).

70 Corporate Value Chain (Scope 3) Accounting and Reporting Standard, section 7.4 ('Tier 1 suppliers have contractual obligations with the reporting company, providing the leverage needed to request GHG inventory data'). Information on contractual provisions is also a voluntary part of the GHG public report (section 11.2).

71 Lin, L. W., "Legal transplants through private contracting: codes of vendor conduct in global supply chains as an example", American Journal of Comparative Law, vol. 57, ed. 3, 2009, 711-744, 717. 
Plc. (BT) imposes the following three minimum expectations upon its contracted suppliers:

- that the supplier has a policy to address the challenge of climate change

- that the supplier is actively measuring and reporting carbon and other green house gas emissions

- that the supplier has set challenging targets to cut emissions and is reporting on progress. ${ }^{72}$

If BT's supplier does not set any carbon reduction targets, it evidently breaches a contract; nevertheless, the delivered goods may still be perfectly compliant with the contract specifications. ${ }^{73}$ The $\mathrm{CO} 2$ reduction targets have thus no direct connection to the main subject of the supply chain contract. Therefore, by the inclusions of CO2 reduction goals, private contracts are balancing on the line between bilateral arrangement and general regulation. This proves to be one of the reasons why it is difficult for scholars and regulators to approach, conceptualize and operationalise them. ${ }^{74}$ This is reflected in, for example, the system of sanctions. If we consider BT's supply agreement as a business contract for delivery of goods, in the case of breach, the main aim of any sanction would be to put the aggrieved party in the position it would have been in had the breach not occurred. The focus would thus be to prevent economic costs to the aggrieved party. If we approach the agreement as a regulation, sanctions will aim to restore the regulatory process, in order to re-establish compliance. ${ }^{75}$

Secondly, supply chain contracts are bilateral instruments. They are private documents, whose confidentiality is often protected by a non-disclosure provision. ${ }^{76}$ Thus, although hundreds of contracts are concluded every day, it may be impossible for an external party to register their existence, monitor their compliance, and eventually enforce the $\mathrm{CO} 2$ reduction requirements therein. Such an external party may not only be a public entity, who wishes to control companies' environmental attitude, but also a third party, who is the actual beneficiary under a contractual provision. ${ }^{77}$ If the third party should have a possibility to defend its rights, knowing about the existence of the

72 BT Plc., Generic Standard 20 Climate Change Procurement Standard, Version 2.0, January 2012, available online at <www.selling2bt.bt.com/Downloads/GS20v2.pdf> (accessed 28 February 2014).

73 This would not be the case if the supplier knows that a product will bear a carbon footprint label and thus the carbon emissions within the manufacturing process should comply with specific maximum levels. In such a case, the emissions level would be a part of the product quality specification and therefore directly connected to the subject matter of the contract.

74 Vandenbergh, M. P., "The private life of public law", Columbia Law Review, vol. 105, ed. 7, 2005, 20292096, 2041-2042, noting that second order agreements (purely private contracts used for achieving public goals) had been overlooked 'because they do not fall neatly into the domain of public or private law scholars'.

75 Cafaggi, F., "The regulatory functions of transnational commercial contracts, New architectures", EUI Working papers series, 2012, 1-32, available online at <papers.ssrn.com/sol3/papers.cfm?abstract_id= 2153096> (accessed 28 February 2014).

76 Lin, supra nt. 71, 743.

77 With regard to environmental protection, the third party beneficiaries will most often mean inhabitants of the locality the pollution takes place in. However, identifying the beneficiary of contractual provision requiring specific targets for $\mathrm{CO} 2$ emissions is more complicated, since climate change is a global problem. Carbon emitted at one place may affect a remote part of the world and thus, it is very difficult to find a causal relationship between the polluting activity and its effects. 
agreement is a necessary precondition (nemo iudex sine actore). This becomes even more problematic in complex international supply chains, where the focal company has a direct contractual relation only with its first tier suppliers and, thus, has no legal rights to monitor its sub-suppliers' behaviour. The difficult accessibility of contractual texts also hinders any empirical research of this issue. ${ }^{78}$

Finally, the climate change mitigation efforts have been focused for a long time on capturing and regulating scope 1 and 2 emissions. These two emissions types have no connection to supply chain contracting and, therefore, contractual governance was not at first considered as a suitable way of regulation. Scope 3 emissions - those that are consequences of the regulated entities' activities, but produced by sources outside of the entities' ownership or control - came into the picture only later. Logically, those emissions would be covered as scope 1 and 2 emissions of the entities which actually produce them. However, due to the misbalance of regulatory activity in various regions, as described above, emissions embedded in imported products (and thus scope 3 emissions associated to purchased goods and services) became the real concern for climate change mitigation. Due to this, supply contracts are gaining more attention.

\section{IV.2. Why Can Contracts Be Successful Where Other Regulations Fail?}

As discussed above, on the one hand, climate change regulation suffers from the nonexistence of binding international law. On the other hand, it is dominated by private regulation with questionable democratic foundation and control, without standardised effective enforcement. Therefore, overall climate change regulation is in an acute need of new regulatory tools and regimes. The author believes that supply chain contracts can be one of the 'old-new' tools that can have surprisingly big positive effects. Old, since contracts are one of the oldest legal instruments, new, since they are increasingly used for new, public purposes. This section describes why supply chain contracting may be more successful than any regulation so far.

\section{IV.2.1. Sustainability Contractual Clauses - Best Practice}

Sustainability clauses are contractual provisions that prescribe minimum social and/or environmental standards to be upheld by contractual parties when performing their business activities. Frequently, these clauses will integrate corporate codes of conduct in order to give the codes the form of binding commitments. ${ }^{79}$ Only a few empirical studies have been conducted to investigate the usage of supply chain contracting for

78 Researchers have to rely on publicly available documents and information provided by companies themselves. Some authors have used data from public databases of corporate documents, such as the U.S. Securities and Exchange Commission (SEC) database. However, the database includes only "material" contracts and supply chain agreements often fall outside of the materiality test. Therefore, the sample may not be representative and thus, it is difficult to make any generalisation. See, e.g. Lin, supra nt. 71; Geis, G. S., "An Empirical Examination of Business Outsourcing Transactions", Virginia Law Review, vol. 96, ed. 2, 2010, 241-300.

79 Vytopil, L., "Contractual Control and Labour-Related CSR Norms in the Supply Chain: Dutch Best practice", Utrecht Law Review, vol. 8, ed. 1, 2012, 155-169, 168 (noting that within their supply chains, companies do not use codes of conduct in the sense of the term, but that they rather intend to gain contractual control); McBarnet, D., Voiculescu, A. and Campbell, T., eds., The new corporate accountability: Corporate social responsibility and the law, Cambridge University Press, Cambridge, $2007,42$. 
sustainability purposes, but all of them agree that contractual control in relation to the social and environmental expectations of multinational companies from their suppliers from developing countries is applied in the majority of business contracts concluded nowadays. Vandenbergh studied contractual practices in relation to environmental issues of companies from eight retail and industrial sectors and found that over $50 \%$ of companies include some type of environmental requirements into their business contracts. These companies mostly include the strongest ones in the specific industry representing about $80 \%$ of the total sales in the given sectors. ${ }^{80}$ A later study conducted by the Pace University and Institute of International Commercial Law showed a rapid increase of these contractual practices, when almost $80 \%$ of the sample companies stated that they had imposed sustainability related requirements upon their business partners and approximately $70 \%$ of them considered including sustainability clauses in their contracts as highly or very important. ${ }^{81}$ Although environmental issues are the prevailing topic in these clauses and managing greenhouse gases appears often ${ }^{82}$ requirements for specific quantified reduction of carbon emissions are only slowly entering the area. ${ }^{83}$

The term 'sustainability contractual clauses' covers a broad spectrum of provisions. Sustainability contractual clauses appear in different forms, as an expressed contractual provision $^{84}$ or a reference to another document, ${ }^{85}$ such as standard terms and conditions,

80 Vandenbergh, M. P., "The New Wal-Mart Effect: The Role of Private Contracting in Global Governance", UCLA Law Review, vol.54, ed. 4, 2007, 913-970. The results are based on an analysis of contractual texts publicly available from the database of the U.S. Securities and Exchange Commission.

81 Pace University School of Law \& IACCM, supra nt. 63, 26. The results are based on a survey conducted with companies representing various industries from North America, Middle East, Africa, Europe, Asia and Pacific.

82 Carbon Disclosure Project, Accenture, REPORT: Supply Chain Report 2012, A New Era: Supplier Management in the Low-Carbon Economy, 2012, available online at <www.cdproject.net/CDPResults/ CDP-Supply-Chain-Report-2012.pdf> (accessed 28 February 2014), 4, stating that half of the responding companies include in their supply chain contracts obligations for suppliers to manage greenhouse gas emissions; however, the number should be interpreted in the context, meaning that the responding companies do not represent an average business behaviour, since they are voluntarily participating in the CDP Supply Chain Program; McBarnet, D., Voiculescu, A. and Campbell, T., supra nt. 79, 65, naming environment to be the "vanguard issue in CSR".

83 E.g. BT recommends to include contractual provision in its purchase agreements that could have the following wording: 'suppliers are expected to have targets to reduce GHGs/carbon emissions by at least $10 \%$ over 3 years or to demonstrate that they have already achieved this and are working to more challenging targets'; see BT Plc., supra nt. 72, article 2.

84 For instance, Mondelez International (former Kraft Food) includes a provision titled Corporate Responsibility Expectations into all contracts with its direct suppliers. In relation to environment it states that '...Supplier will work to continuously improve its environmental performance by setting and then working toward quantifiable goals that reduce the environmental impact of its activities'. The full wording of the provisions is available through Mondelez International, Corporate Responsibility Expectations for Direct Suppliers, available online at <global.mondelezinternational.com/deliciousworld/ compliance-integrity/corporate_responsibility_expectations.aspx > (accessed 28 February 2014).

85 A two-step reference system often appears, meaning that a contract for example refers to standard terms and conditions, which then refer to a code of conduct. An example can be found in article 13 of General Terms \& Conditions of Purchase of Goods of Unilever Supply Chain Company AG ("Conditions"), filed at the Handelsregister in Schaffhausen, Switzerland under number 249.4.001.616-4, available online at <www.unilever.com/aboutus/supplier/termsandconditions/> (accessed 28 February 2014): 'Each Supplier and the Lead Supplier acknowledges that it has reviewed Unilever's Supplier Code (the 'Code') and agrees that all of their activities shall be conducted in accordance with the Code...'. 
a code of conduct, ${ }^{86}$ another internal policy, ${ }^{87}$ a global CSR initiative, ${ }^{88}$ or a separate agreement. ${ }^{89}$ They also have different content, most often related to environmental standards, employment conditions, health and safety standards, human rights and business ethics issues. ${ }^{90}$ Their scope of applicability varies to a great extent; many of them extend beyond a bilateral agreement and impose or drive the obligations to further members of the supply chain. ${ }^{91}$ The provisions are also accompanied by different monitoring and enforcing mechanisms, ranging from soft relational tools to hard contractual sanctions. ${ }^{92}$

86 For example, Bayer Group states in relation to Suppliers' Code of Conduct the following: 'It is a fixed element of our supplier selection and evaluation process, and is integrated as binding into our electronic ordering systems and contracts throughout the Group through a special clause', see Bayer Group, Sustainability Development Report 2011, available online at <www.sustainability2011.bayer.com/en/ homepage.aspx> (accessed 28 February 2014), 31.

87 Supra nt. 72: '[i]f this Generic Standard ('GS20') is referenced in any contract you have with BT ('Contract'), you, as the Supplier, agree to...'.

88 For example, Pressalit Group requires from its suppliers that 'with the design of the products and with the choice of materials, production methods, employees and sub-contractors, the seller must ensure that buyer's environmental policy is complied with. Furthermore compliance with UN's Global Compact should be observed', see Pressalit Group A/S, General Purchasing Terms, available online at $<$ www.pressalit.com/NR/rdonlyres/0FFF18D6-6FE7-4A07-A67F-

E21EDE90C31A/0/Indkøbsbetingelser_ENG.pdf> (accessed 28 February 2014).

89 For example, Hewlett Packard, HP's Supplier Social \& Environmental Responsibility Agreement, 22 October 2008, available online at <www.hp.com/hpinfo/globalcitizenship/environment/pdf/ supagree.pdf $>$ (accessed 28 February 2014).

90 Pace University School of Law and IACCM, supra nt. 63, 29. 82.4\% of the responding companies include environmental standards into their SCCs, followed by $80.4 \%$ including health and safety standards, $76.5 \%$ employment laws and 51\% human rights. Other issues were included by less than $32 \%$ of responding companies.

91 Companies differ in the level to which they pass the responsibility for sustainable supply chain on its suppliers. On the one side of the spectrum, EADS demands its suppliers to ensure compliance of the whole supply chain (see Airbus Group, EADS Corporate Social Responsibility in Sourcing - EADS CSR Sourcing Provisions, 1 October 2010, available online at <www.eads.com/eads/int/en/ourcompany/Our-suppliers.html> (accessed 28 February 2014), art. 7: 'The Supplier ensures that the EADS CSR Sourcing provisions defined herein are also observed by all their subcontractors and suppliers. EADS relies on the Supplier to communicate and promote actively EADS CSR Sourcing provisions through their entire supply chain.'). On the other side of the spectrum, Vodafone only "encourages" dissemination of its code throughout the supply chain (see Vodafone, Vodafone Procurement Company S.à r.1., Supplier Policy - A2, Code of Ethical Purchasing, version 3.0, 6 September 2013, available online at <www.vodafone.com/content/index/about/aboutus/suppliers/our_policies_processes_and_tools.html> (accessed 28 February 2014), art. 2.3: 'Supplier is encouraged to take all reasonable endeavours to promote this Code to its suppliers and subcontractors.'). Heineken stands in the middle, expecting its suppliers to enforce compliance only from their own suppliers, i.e. second tier suppliers (see Heineken, Supplier Code, 8 July 2010, available online at <www.theheinekencompany.com/sustainability/governance/our-policies> (accessed 28 February 2014): '. . they (suppliers) shall take all appropriate steps to ensure that their own suppliers live by the key elements of the Supplier Code...').

92 For example, Telecom Italia Group implements a full range of monitoring and enforcement tools during both pre-contractual and contractual phase. These tools include, inclusion of CSR criteria into suppliers' selection process, suppliers' self-assessments, on-site audits (both internal and external), corrective plans, and contractual sanctions (penalties, reduction of supply volumes and eventually termination), see Telecom Italia Group, Suppliers Policy in the Purchasing Process of the Telecom Italia Group, available online at <www.telecomitalia.com/content/dam/telecomitalia/documents/ Sostenibilita/en/Policies_ENG/Suppliers_EN_22.12.09.pdf $>$ (accessed 28 February 2014). 
All these features influence provisions' binding power and, thus, enforceability. However, the fact that they exist and that their use is widespread, suggests that a certain best practice regarding their use has developed among companies. The best practice will generally include presenting clear expectations to suppliers, implementing these expectations throughout the whole relationship with suppliers from their selection, contract negotiation and compliance control during the contract term, continuous or regular communication on suppliers' progress, relational attitude towards enforcement with focus on mutual transparency and support and leverage in the form of the possibility to terminate the business relationship in case of on-going non-compliance. ${ }^{93}$ There is no obstacle for extending the best practice to the new carbon emissions related provisions. The up-to-date experience with sustainability contractual clauses provides companies with negotiation and implementing processes and monitoring and enforcement tools for making the best out of the contractual control. Through contractual control, they may trigger changes in suppliers' behaviour without losing the economic benefits of outsourcing the specific part of their business activities. Therefore, inclusion of one more topic or a specific goal into the provisions can easily be done without additional negotiation or administration costs. Suppliers are used to these types of obligations and, thus, it may be expected that they will not oppose an inclusion of another one. Moreover, they are often not in the economic position to oppose such requirements. Finally, compliance with carbon emissions' reduction requirements may bring economic benefits to suppliers. ${ }^{94}$ Of course, the monitoring and enforcement costs may rise due to the necessity of having specialised processes to count the carbon emissions. But also this obstacle does not seem to be problematic since several guidelines exist on calculating and assessing corporate scope 3 emissions, with the already mentioned GHG Scope 3 Standard being probably the most detailed one. ${ }^{95}$

To summarise the above, businesses are nowadays used to implementing various sustainability requirements into their supply chains. Companies and other public and private entities have developed best practices based on their practical experience in this area, meaning that there is a body of literature dealing with the best ways to align supply chain members with companies' ethical, social and environmental standards. The best practice deals with a broad scope of requirements and it can easily be utilised to manage new requirements such as those for carbon emissions' reduction.

\section{IV.2.2. Enforceability through contract law}

Companies include requirements for the reduction of carbon emissions into supply chain contracts, as is similar in the case of other sustainability related obligations, in order to gain a legal leverage over their suppliers' behaviour. In fact, most suppliers from

93 Network for Business Sustainability, Brammer, S., Hoejmose, S., Millington, A. and NBS, Managing sustainable global supply chains, Framework and Best Practices, 2011, Ontario, Canada, available online at <nbs.net/wp-content/uploads/NBS-Executive-Report-Supply-Chains.pdf> (accessed 28 February 2014); UN Global Compact Office and Business for Social Responsibility, Supply Chain Sustainability, A Practical Guide for Continuous Improvement, June 2010, available online at <www.unglobalcompact.org/ docs/issues_doc/supply_chain/SupplyChainRep_spread.pdf $>$ (accessed 28 February 2014); Pace University School of Law \& IACCM, supra nt. 63, 28-29.

94 In 2012, $73 \%$ of the CDP Supply Chain Program members reported monetary savings (in comparison to $39 \%$ in 2011), suppliers could expect to reach comparable results; see CDP, supra nt. 47, 14.

95 Other guidelines were developed e.g. by U.S. Environmental Protection Agency or by private company Carbon Trust. 
developing countries have no legal obligation from public regulation in relation to carbon emissions. Therefore, if buyers from developed countries wish to change suppliers' behaviour, they have to exert enough pressure to effectively compensate for the absent binding regulation. In order to do so, companies combine several types of leverage: economical, relational and legal. They are all closely interrelated and reinforce each other.

The economic leverage stems from the fact that suppliers from developing countries are highly dependent on a multinational buyer. ${ }^{96}$ The enormous economic power asymmetry gives the buyer the possibility to basically unilaterally dictate conditions of the business relationship. ${ }^{97}$ Therefore, the supplier strains to comply (or at least appear to do so), because such a business relationship may be the determining point of his existence.

The relational leverage is exercised through long-term business relationships, where a buyer invests resources in educating and developing its suppliers, and in return expects the suppliers to be loyal and follow the buyer's requirements. This type of cooperation, where both parties invest into the relationship and therefore develop certain social norms of cooperation between them, ${ }^{98}$ was described in the relational contract theory of Ian R. Macneil. ${ }^{99}$ The failure of such a relationship is detrimental to both parties, regardless of the economic misbalance.

The legal leverage is facilitated through the possibility of enforcing agreed terms of cooperation before courts. The economic and relational pressure is usually effective. However, buyers having at stake not only their money but also their good name, wish to ensure that suppliers will be aware of the costs of non-compliance. In case of court proceedings, these may raise to a significantly higher amount than the actual damage caused by non-compliance. In case of carbon emissions reduction requirements, the actual damage is hardly ever possible to be proven. Typically this is due to a missing or blurred causal link. ${ }^{100}$ Nevertheless, in a court proceeding, the buyer may claim compensation for both suffered and future reputational damage, loss of profit and the costs of proceedings. ${ }^{101}$ Therefore, the contractual form is used to frame the requirements

96 However, such economic inequality is not so frequently the case in regards to domestic suppliers or suppliers of a highly specialised components or goods where no alternative source is available.

97 McBarnet et al., 2007, supra nt. 79, 86-88, noting how few negotiation power suppliers from developing countries have when dealing with strong buyers from developed countries; Kessler, F., "Contracts of Adhesion - Some Thoughts About Freedom of Contract", Columbia Law Review, vol. 43 ed. 5, 1943, 629-642, comparing the unilateral imposition of contractual conditions to legislative activity.

98 Gudel, P. J., "Relational Contract Theory and the Concept of Exchange", Buffalo Law Review, vol. 46, ed.3, 1998, 763-798, 786, referring to norms of relational contract developed by Macneil, i.e. role integrity, reciprocity, implementation of planning, effectuation of consent, flexibility, contractual solidarity, protection of restitution, reliance and expectation interests, creation and restraint of power, propriety of means and harmonisation with social matrix; Gudel, 782, sees these norms as 'generated by the contractual relation itself and related to the relation in a functional way...'.

99 Macneil, I. R., The new social contract: an inquiry into modern contractual relations, Yale University Press, New Haven, 1980. Next to Macneil, Stewart Macaulay has contributed extensively to development of the theory.

100 An actual damage could be proven in case that the delivered product is to be labelled with a low-carbon label that the supplier knew about and the delivered goods is not compliant with the label's conditions.

101 Schwenzer, I., Leisinger, B., "Ethical Values and International Sales Contracts", in: Cranston, R., Ramberg, J. and Ziegel, J., eds., Commercial Law Challenges in the 21st Century: Jan Hellner in memoriam, Stockholm Centre for Commercial Law, Juridiska Institutionem, Stockholm, 2007, 268-270, discussing 
for reduction of carbon emissions as a binding obligation. Although sustainability clauses are not generally enforced through courts, ${ }^{102}$ the option itself has an impact on the perception of the obligation by suppliers and enhances their compliance. ${ }^{103}$ This is an expression of Olivecrona's understanding of the binding force of law as being only '.. an idea in human minds' ${ }^{104}$ Nevertheless, the idea is supported by the underlying legal framework.

Even though many differences between individual jurisdictions exist, the main principles of contract law are similar around the globe; these include the principle of contractual freedom, the underlying moral imperative pacta sunt servanda and the enforceability of contracts through public legal institutions. The legal system for contractual enforcement copes rather well with the growing number of inter- and transnational private transactions. In most cases, where parties do not choose applicable law, international default law will apply. ${ }^{105}$ Despite some inherent flaws of the international law of contracts, ${ }^{106}$ the system is rather clear, accessible to private parties and tailored for international business relations. Therefore, provided that a contractual provision does not prescribe anything illegal or impossible, it should theoretically be enforceable under the international law of contracts. ${ }^{107,108}$

In sum, the international contract law system serves to create legal leverage over suppliers' behaviour and concurrently a safety net for buyers in the case that the economic and relational leverage fail. It should be noted here that each type of pressure, and especially the economic pressure, can be used both for good and bad purposes. ${ }^{109} \mathrm{In}$ this paper, the author works with the idea to use the pressure for achieving positive

the possibility to claim damages in case of breach of a contractual clause banning child labour in the production process.

102 McBarnet et al. 2007, supra nt. 79, 79; Cafaggi, F., "The Architecture of Transnational Private Regulation", EUI Working Paper, LAW 2011/12, European University Institute, 2011, 9; Lin, supra nt. 71, 725.

103 Peterkova, K., Sustainability Clauses in International Business Contracts, PhD thesis, Aarhus University, Denmark, forthcoming 2014 (discussing legal and psychological processes that are triggered by the fact that a contractual provision is perceived as binding).

104 Ratnapala, S., Jurisprudence, Cambridge University Press, Melbourne, 2009, 113 (Describing perception of binding force of law by a representative of Scandinavian legal realism Karl Olivecrona.)

105 Most often, the United Nations Convention on Contracts for the International Sale of Goods, 1980, 1489 UNTS 3.

106 Unified interpretation and application is one of the most problematic issues.

107 See Schwenzer and Leisinger, supra nt. 101.

108 The enforceability could be questioned based on the specificity level of a given provision. It would certainly make a difference, if a provision states that 'Supplier is obliged to reduce carbon emissions produced during manufacturing process of the product by $5 \%$ compared to carbon emissions level in 2011 and document the reduction by detailed documentation" and "Supplier shall make the best effort to monitor and reduce its carbon emissions'. In the second case, a court could refuse the claim based on the argument that the provision does not prescribe any actual obligation. This discussion is not new and does not pertain only to provisions related to environment, human rights, or ethical standards. A whole scholarship on similar issue exists in relation to e.g. recitals in contracts; see Fontaine, M. and De Ly, F., Drafting Commercial Contracts: An Analysis of Contract Clauses, Martinus Nijhoff Publishers, Leiden, Boston, 2009. However, this discussion reaches outside the scope of this article.

109 McBarnet et al., supra nt. 79, 88, noting that the buyers sometimes require the suppliers on the one hand to adhere to CSR standards and on the other press on low price and tight delivery deadlines, so that they basically force the suppliers to breach the CSR standards. 
results in the climate change area. In order to eliminate the possibility of using it in a negative way, national legal regulation should give companies the right incentives.

\section{IV.2.3. Overcoming deficiencies of private regulation}

As described above, the climate change area is dominated by private regulation that suffers from several deficiencies with regard to its legitimacy, effectiveness, and monitoring and enforcement. Giving an obligation a form of contractual provision may help to cope with these deficiencies.

Firstly, the question of unclear legitimacy typical of transnational private regulation does not emerge in a contractual relation. Contracts are products of negotiation and agreement between contractual parties that set the rules for their mutual relation on the background of the legal order. It is the legislator, the creator of contract law that vests in the parties the right to govern their business relationship. This is theoretically true, albeit practice may appear different, since a majority of contracts concluded within international supply chains may not be products of negotiation but rather unilaterally imposed rules by economically stronger parties. ${ }^{110}$ Moreover, requirements for carbon emissions reduction do not affect only the contractual parties but directly influence the life of third parties; global citizens. ${ }^{111}$ Thus, we could discuss whether contractual parties have the authority to govern climate change issues. I tend to argue that this should not be an issue, because unlike private regulatory regimes, contracts impose obligations only on the parties who agree to them. They cannot oblige external subjects to adhere to a bilateral arrangement; these subjects may only benefit from the results. However, this is only a valid opinion in the case where contracts are not the only regulation in the area, when states do not entirely pass the regulation on private parties. Contractual clauses and their enforcement are vulnerable and can easily be influenced by the economic interests of the contractual parties, and therefore although they contribute to positive changes in the environment, they should be rooted in a broader regulatory system.

The second problematic aspect of private regulation, effectiveness, is in the case of contracts supported by system of contractual monitoring and sanctions. Compliance control is, similarly to private regulation, ensured by companies themselves. This leaves space for doubts, although the system of sanctions based on both contractual text and background law suggests a higher possibility of reaching the intended effects. The fact that all three types of pressure - economic, relational and legal - are applied at once, promises a higher responsiveness on the suppliers' side. This issue is closely connected to that of enforceability as a third area challenging private regulation, which was already discussed in the previous sub-section.

Even though contractual form does not solve all the disputable features of private regulation, it scores better in all of them. This is also the reason why private regulation is frequently implemented through contracts, as contractual form strengthens the pressure on compliance.

\section{IV.2.4. Lower Adoption Costs}

Supply chain contracts represent a unique regulatory technique that does not employ high adoption costs. There is no need for lengthy negotiations and legislative processes,

\footnotetext{
110 See supra nt. 97.

111 Lin, supra nt. 71, 742-742, discussing the accountability problems in legal transplants via private contracts that affect third parties.
} 
as in the case of international and national legislation. While the business community has the possibility to lobby against the adoption of new strict regulation in the climate change area, it does voluntarily enter into private contracts with the same or similar requirements. The reason is that the content of private contracts can be adjusted to each specific company's needs and interests. Furthermore it depends on each company whether it enforces the contract or not, while in the case of public legislation enforcement is carried out by public authorities. Adoption of carbon reduction requirements into contracts can thus be also seen as a strategy to lull governments and the public into a false sense of security that the problem has been dealt with and no further regulation is needed. ${ }^{112}$

\section{IV.2.5. Interaction with other regulation}

Finally, contracts have a special position within other regulations, both public and private. On the one hand, they can give soft private regulation a hard law edge if implemented in contract by reference. For example, if a buyer requests its suppliers to report on carbon emissions according to the CDP guidelines, the CDP guidelines gain binding character and can be enforced through contractual sanctions. ${ }^{113} \mathrm{On}$ the other hand, contractual practice can be influenced easily by public regulation. If a national law requests companies to report on their supply chain emissions, they will have to use available tools for gaining the data of their suppliers. As already discussed, contracts are probably the best means to use. Therefore, contracts may serve as a bridge between the public and private law, and between soft and hard law.

\section{Quantifying Potential For Emissions' Reduction Through Contracts}

Considering the above, it seems that contracts are overall better equipped to achieve reduction of carbon emissions of suppliers in developing countries than many existing public laws or private regulations. The question is whether the possible emission reductions are significant enough to justify devoting more attention to contractual governance. To answer this question is not easy. As it was already outlined in Section III. above, scope 3 emissions contribute significantly to global emissions. Though how much emissions are we actually talking about, and how much of these can be cut through contractual control?

In order to assess how much carbon emission could be cut through requirements in supply chain contracts, we must first know the overall volume of carbon emissions that supply chains are responsible for. This proves to be a much more complicated calculation than it could seem at first sight for several reasons. First and foremost, international supply chains are often extremely complex, including numerous companies from various jurisdictions. It is not unusual that a buyer does not know which subjects are members of

112 Reich, R. B., "The Case Against Corporate Social Responsibility", Goldman School of Public Policy Working Paper No. GSPP08-003, 2008, showing the involvement of enterprises in lobbying against adoption of new regulation within the CSR area.

113 See practical example from Pressalit's policies giving contractual form to the UN Global Compact, supra nt. 88. 
its supply chain. ${ }^{114}$ Moreover, one company can have different supply chains for each product. Multinational companies thus have thousands of suppliers. A supplier then does not manufacture products or components for one buyer only at one time. Therefore, it can be extremely difficult or even impossible to allocate emissions among various buyers. ${ }^{115}$ Even if companies know all supply chain members, they face the practical obstacle of having contractual relationships only with first tier suppliers; other tiers are connected only indirectly and thus the focal company cannot request information from them, and sometimes must rely on secondary data. ${ }^{116}$

Although difficult, assessing supply chain emissions is not impossible. ${ }^{117}$ Researchers, companies and regulators have provided several estimates of the scope 3 emissions volume. Even though they differ in absolute numbers, they generally agree that scope 3 emissions comprise a majority of total corporate emissions. Matthews et al. found that scope 1 and 2 amounts in average to $26 \%$ of all emissions, leaving $74 \%$ to emissions from supply chains. ${ }^{118}$ According to CDP, supply chains accounts for $50-70 \%$ of companies' total emissions. ${ }^{119}$ Trucost's data show that supply chains are responsible for at least $75 \%$ of total emissions. ${ }^{120}$ Companies sometimes propose even higher numbers. For instance, BASF Group reported approximately $85 \%$ of its emissions originate in the supply chain ${ }^{121}$ and Mondelez International (previously Kraft Foods Inc.) estimated that scope 3 represents over $90 \%$ of its overall emissions. ${ }^{122}$

However, not all scope 3 emissions can be assigned to suppliers or influenced by supply chain contracting. The CDP Scope 3 Standard distinguishes between upstream and downstream scope 3 emissions and overall introduces fifteen categories: upstream supply chain's emissions include purchased goods and services, capital goods, fuel and energy related activities, transportation and distribution, waste generated in operation,

114 Walmart describes the problematic of unknown members in its supply chain in the 2012 Global Responsibility Report: Beyond 50 years: Building a sustainable future, 41: "Undisclosed subcontracting is defined as factories in our supply chain that produce merchandise or component items for Walmart in a facility that is improperly disclosed and/or unknown to Walmart. There are signs that this practice may be on the rise in countries including, but not limited to, Indonesia, China and Pakistan. The potential impact of undisclosed subcontracting is that illegal and unethical practices can be more easily hidden".

115 GHG Scope 3 Standard, section 8.

116 Id., section 7.3.

117 Nevertheless, some companies prefer to not engage in scope 3 emissions calculations. For example, IBM states on its website that the assumptions necessary to be made for estimation of scope 3 emissions do not allow for an estimate that would be adequately credible and have necessary quality; see IBM, Position on Scope 3 GHG emissions, available online at <ibm.com/ibm/environment/climate/ scope3.shtml> (accessed 4 November 2013).

118 Matthews, H. S., Hendrickson, C. T. and Weber, C. L., "The Importance of Carbon Footprint Estimation Boundaries", Environmental Science \& Technology, vol. 42, ed. 16, 2008, 5839-5842, 5840.

119 Carbon Disclosure Project, supra nt. 47, 9, referring to US Environmental Protection Agency, REPORT: Managing Supply Chain Greenhouse Gas Emissions, December 2010.

120 Trucost, Supply chain carbon briefing, GHG Protocol Scope 3 Standard, Measuring indirect carbon emissions to build more sustainable business models and brands, available online at <trucost.com/_uploads/publishedResearch/Supply_chain_carbon_briefing_060312_D.pdf> (accessed 4 November 2013).

121 BASF Group, Greenhouse gas emissions - balanced along the value chain in line with the Greenhouse Gas Protocol, available online at <basf.com/group/corporate/en/sustainability/environment/climateprotection/bilanzierung-treibhausgasemissionen $>$ (accessed 4 November 2013).

122 Carbon Disclosure Project, supra nt. 82, 8. 
business travel, employee commuting and leased assets and downstream supply chain's emissions include transportation and distribution, processing of sold products, use of sold products, end-of-life treatment of sold products, leased assets, franchises and investments. ${ }^{123}$ Some of these categories are easier to measure (e.g. business travels and employee commuting), but some request a more complex approach and data from other subjects (e.g. purchased goods and services). According to the data of the Environmental Investment Organisation, only one company (BASF Group) reported in 2010 on all fifteen categories of scope 3 emissions. ${ }^{124}$ Most companies started to report on the easier ones and slowly extended the practice across more categories.

Supply chain contracting can generally influence the first four categories. The most important category for this article is the first category - purchased goods and services. Although the distribution of scope 3 emissions among the different categories depends greatly on the product (or industry) in question, ${ }^{125}$ purchased goods and services commonly represent the largest portion of scope 3 emissions. In 2011, BASF Group reported that purchased goods and services accounted for 61.700 .000 tons of CO2e, which represents $41 \%$ of all scope 3 emissions and almost two and half times more than corporate scope 1 and 2 emissions together. ${ }^{126}$ Mondelez International (previously Kraft Foods Inc.) reported that purchased goods and services are responsible for ca. $70 \%$ of its scope 3 emissions, which represents six times its scope 1 and 2 emissions. ${ }^{127}$

The example of BASF Group shows that calculating scope 3 emissions in detail in relation to each single category (including purchased goods and services) is viable. Most categories can be calculated using mainly primary, company-specific data. ${ }^{128}$ But that seems almost impossible in relation to purchased goods and services. Firstly, calculation of emissions embedded in purchased goods and services depends to a large extent on obtaining data from suppliers. Secondly, due to the complexity of international value chains and the necessity of allocating each supplier's emissions among multiple buyers, the estimate must use some type of mathematical model, and work with certain assumptions. Therefore, although we see that companies increase their efforts to get to know, report and reduce their upstream supply chain emissions, only few of them actually conducted a detailed carbon inventory in respect of purchased goods and services. It is a lengthy and costly process. Thus, at this moment we can find only scarce information on carbon emissions embedded in purchased goods and services in absolute numbers. Nevertheless, we know that these emissions constitute a more urgent problem than scope 1 and 2 emissions of internationally operating companies. The question is

${ }^{123}$ GHG Scope 3 Standard, supra nt. 29, section 5.3 (overview) and 5.4 (description).

124 Environmental Investment Organisation, ET Global 800, 2011, available online at <eio.org.uk/etindex.php?page=overview1\&ranking=Global_800 $\geq$ (accessed 4 November 2013).

125 For example, chemical products emit substantially more emissions during their use by end users than for example food products. The distribution of emissions along the life cycle of each product is unique. Nevertheless, we may generalise to certain point on the industry level.

126 The numbers have improved rapidly in 2012, when purchased goods and services amounted only to 46.670.000 tons CO2e representing $36 \%$ of the scope 3 emissions, see BASF Scope 3 GHG Inventory Report, available online at <basf.com/group/corporate/en/function/conversions:/publishdownload/ content/sustainability/environment/climate-protection/images/BASF_Scope3Report.pdf $>$ (accessed 4 November 2013).

127 Carbon Disclosure Project, supra nt. 82, 8.

128 Secondary data include e.g. industry statistics, inventory data or input-output models. 
how this problem can be tackled. What can be done without exact knowledge of full scope 3 emissions?

Here the contractual governance comes into focus. Some companies start by giving their suppliers qualitative rather than quantitative requirements, for example to monitor and report on their carbon emissions. ${ }^{129}$ This is certainly an important first step. However, it does not ensure that suppliers will actually reduce their emissions. One step further is when companies inform their suppliers that compliance with emissions related requirements (either qualitative or quantitative) will be a criterion for awarding a contract. ${ }^{130}$ But only using quantitative requirements can make a more significant change. One good thing is that companies do not necessarily need to know the emissions rate of each single member of their supply chain to introduce a contractual demand for a five percent reduction of carbon emissions over a specified period of time. Furthermore, this should not be complicated for suppliers, who need to calculate merely their scope 1 and 2 emissions, which they can rather easily document, and pass the demand further among their own suppliers. Not being able to document requested reductions then means that a supplier may not enter into a contract with the specific buyer at all or that it may lose already existing business if the buyer terminates the contract due to non-compliance in line with the best practice in the sustainability area. Such a request, provided that it is closely controlled, may actually offer much quicker solutions without the necessity to master the complex supply chain data first. Of course, companies must have some type of overview of their activities and reduction capacities of their suppliers at the outset to choose adequate and feasible goals; however, they may rely in many instances on industry based data.

\section{Conclusion}

The article has discussed the possibility to use supply chain contracts as a regulatory means to lower global carbon emissions. As Section II-IV show, contracts are better equipped to tackle the global emissions problem than many of existing private and public regulations. Section $\mathrm{V}$ then provided a brief insight into the amount of carbon emissions we are speaking about in relation to international supply chains. Overall, contractual requirements for reduction of companies' direct suppliers' emissions by a few per cent seems more feasible than requesting suppliers to provide an accurate carbon inventory of all their supply chains. However, several questions remain to be answered.

129 T\&T, Sustainability report 2011, available online at <att.com/gen/landing-pages?pid=22872> (accessed 4 November 2013), 46: 'We are aware of the publication of the Greenhouse Gas Protocol's Corporate Value Chain (Scope 3) standard and are exploring how to apply it to our business. To that end, we are working with the Carbon Disclosure Project (CDP) Supply Chain Initiative to measure the emissions from our top suppliers. Each year we send the survey to suppliers who represent approximately 80 percent of our total spend. We know that as of year-end 2011, 60 percent of our spending was with suppliers who track GHG emissions or had plans to do so by 2012. We've set a goal that by the end of 2015, the majority of our spending with strategic suppliers will be with those who track GHG emissions and have specific GHG goals. Read more about our efforts to engage our supply chain.'

130 Jira, C. F. and Toffel, M. W., "Engaging Supply Chains in Climate Change", Working Papers 12-026, Harvard Business School, 2012, forthcoming in Manufacturing \& Service Operations Management. The authors found that suppliers are more willing to share information on their climate change performance if buyers convey a commitment to use these information in their purchasing decisions. 
Firstly, how this contracting practice can be triggered? The current practice shows that companies feel an external pressure to engage in carbon reduction in their supply chains. However, the practice is in its infancy. It is not standardised and is dependent on decisions of each specific company, and therefore develops rather slowly. For scaling up the effects of supply chain contracting, a stronger or maybe better, more urgent incentive should be given to companies to accelerate the diffusion of the contractual practice. The incentive can most probably be given by a public regulation on national level that will indirectly demand increased contractual control in international supply chains. Such regulation can include transparency requirements through demanding of scope 3 emissions disclosure or mandatory carbon labelling, which would also make the legal enforcement of the contractual requirements easier. It may however be more direct to include supply chains emissions into cap and trade schemes, or implement carbon pricing relevant to embedded emissions in imported products. If the business community opposes these policies, then positive incentives, for instance lower value added tax on products with low embedded carbon levels or provision of guidelines and assistance with drafting contractual requirements, could be favoured.

The second question is how the contracts should be drafted, monitored and enforced to ensure the best possible result? Contractual provisions requesting reduction of carbon emission in a supplier's manufacturing process or its business conduct generally are different from other obligations prescribing contractual clauses. As mentioned earlier, they differ in the type of protected interests as well as in their enforceability. Although it has been suggested that relational contracting can achieve the best effects, the possibility of contract termination still plays an important role. However, we need more research to be done in examining which types of contracts (complete or incomplete, discreet or relational) and provisions (expressed, reference to other document) suppliers respond the best. This will most probably include research into behavioural aspects of contracting and, thus, other research areas than law.

Finally, we should ask if the same attention should be given to all sectors, or if specific sectors should be prioritised? Is it more feasible to target one industry at a time? Or shouldn't we build upon already established industrial initiatives? Once again, this issue needs a more research to be done.

To conclude, the article has shown how the climate change regulatory matrix may benefit from more attention devoted to supply chain contracts. They may serve as the missing piece in the puzzle, and bridge between public and private regulation. It is a feasible solution without the necessity to reach complicated international agreements, without increasing public regulatory costs, and increasing corporate costs only slightly. They can also be implemented immediately without waiting for complementing complex carbon inventories, since nowadays each company can count its scope 1 and 2 emissions rather easily and document achieved cuts. The quantified estimates of scope 3 emissions suggest that a large potential for carbon emissions reduction exist in international supply chains. Therefore, we should focus on how this great latent potential can be triggered through private contracting. 